\title{
Pattern of Blood Pressure Distribution among University Students in Ajman,
}

\section{United Arab Emirates}

\author{
Basha A S1, Mathew E2,Sreedharan ${ }^{3}{ }^{3}$, Muttappallymyalil J4, Sharbatti A S5,Shaikh B R ${ }^{6}$
}

${ }^{1}$ Specialist and Head, Department of Internal Medicine, Gulf Medical College Hospital and Research Centre, Ajman, UAE.

2Professor, Department of Community Medicine, Gulf Medical University, Ajman, UAE.

${ }^{3}$ Assistant Director, Research Division, Gulf Medical University, Ajman, UAE.

${ }^{4}$ Research Associate, Research Division, Gulf Medical University, Ajman, UAE.

5Professor and Head, Department of Community Medicine, Gulf Medical University, Ajman, UAE.

${ }^{6}$ Assistant Professor, Department of Community Medicine, Gulf Medical University, Ajman, UAE.

\section{Original Article}

\section{Corresponding Author:}

Dr. Jayadevan Sreedharan, PhD

Assistant Director, Research Division

Gulf Medical University, Ajman, UAE

Email: drjayadevans@gmail.com

\section{Abstract}

\section{Background}

Elevated blood pressure has been identified as a silent killer contributing to mortality and morbidity worldwide, hence it is essential to identify the high risk individuals at an early age to prevent the progress of the disease and its co-morbid conditions.

\section{Objective}

The objective of the present cross-sectional study was to assess the pattern of blood pressure distribution among students of medical and allied health professions at Gulf Medical University (GMU) Ajman, United Arab Emirates (UAE).

\section{Methods}

The study was conducted from November 2009 to February 2010. GMU has academic programmes such as Bachelor of Medicine, Physical therapy, Pharm D and Dental Medicine with a multiethnic student population. A pretested structured instrument used for data collection and blood pressure was measured using mercury sphygmomanometer. Descriptive statistics such as means and standard deviation were used to summarize the quantitative variables. The association of age, gender and nationality with systolic and diastolic blood pressure was determined by Pearson's correlation coefficient and a $p$ value $\leq 0.05$ was considered statistically significant.

\section{Results}

The systolic and diastolic blood pressures were evenly distributed across all students irrespective of their age. A significantly higher systolic blood pressure in males was observed when compared to females, but the difference was not significant in diastolic blood pressure. In the present study among medical and allied health science students, the distribution of blood pressure was not associated with age. The mean systolic blood pressure and diastolic blood pressure were seen to be higher among Arabs when compared to Non-Arabs though not statistically significant. Family history of metabolic diseases did not show any association with the mean blood pressure.

\section{Conclusion}

There was a strong association for developing hypertension among male when compared to female gender.

Key Words: University students, Age, Gender, Nationality, Systolic blood pressure, Diastolic blood pressure

\section{Background}

The term blood pressure refers to the pressure of blood against the walls of the arteries which results from two forces: one created by the heart as it pumps blood into the arteries through the circulatory system and the second one is the force exerted by the arteries as they resist the blood flow $^{1}$. Elevated blood pressure during childhood and adolescence is not a rare phenomenon and increases the chance for hypertension in adulthood ${ }^{2}$. High blood pressure is identified as a major modifiable risk factor for heart 
disease and the most important risk factor for stroke ${ }^{3}$. Elevated blood pressure is a growing public health issue across the world ${ }^{4}$ and accounts for $6 \%$ of deaths worldwide 3 . Prevalence data available from western population shows $33.5 \%$ in non-Hispanic blacks, $28.9 \%$ in non-Hispanic whites, and $20.7 \%$ in Mexican Americans. The incidence is on the increase in Asian countries ${ }^{5}$ however very few studies have been carried out among multiethnic population in countries other than United States.

The prevalence of hypertension in male youth was $1.6 \%$ in a study conducted in Singapore ${ }^{6}$. The estimate in the Asia Pacific Region showed in 2005 that the mean systolic blood pressure (SBP) for people aged $30-44$ was on the rise ${ }^{7-8}$ and the general trend observed was that females had lower mean SBP values than males. High blood pressure is a leading risk factor for cardiovascular disease. High blood pressure in adulthood may be associated with the blood pressure elevation at a younger age ${ }^{9}$. Estimation and management of blood pressure in younger age group has therefore been strongly recommended to enhance cardiovascular health in adulthood ${ }^{10}$.

Elevated blood pressure has been identified as a silent killer contributing to mortality and morbidity worldwide, hence it is essential to identify the high risk individuals at an early age to prevent the progress of the disease and its co-morbid conditions ${ }^{3}$. Inculcation of healthy habits at an early age will help to reduce the risk of pre-hypertension and subsequently overt hypertension and its associated complications at later stage.

The present study was conducted to determine blood pressure distribution among university students with specific reference to non modifiable factors such as age, gender, and nationality. The findings of this study provide an insight into the pattern of blood pressure in youth and will help in determining the need for early and regular blood pressure monitoring, especially in this age group.

\section{Materials and methods}

\section{Study setting:}

This cross-sectional study was conducted at GMU, Ajman, UAE from November 2009 to February 2010. GMU has the following undergraduate academic programmes such as Bachelor of Medicine, Physical therapy, Pharm D and Dental Medicine with a multiethnic student population.

\section{Subjects:}

This study was conducted in the first year of the programme in the GMU, in the year 2009. All students registered in the first year of their studies in various academic programmes such as Medicine, Dental Medicine, Pharmacy and Physical therapy who were present on the day of conducting the study consented to participate in it.

\section{Research instrument:}

The pretested structured instrument used for data collection contained both open-ended and close-ended questions. Socio-demographic characteristics like age, gender, nationality and country of origin were obtained from the participants before subjecting them for blood pressure measurement.

\section{Blood pressure measurement:}

The blood pressure was measured after making the subjects comfortably seated in a chair, with arms supported at heart level. Appropriate cuff size was used to obtain an accurate measurement. Blood pressure was measured using mercury sphygmomanometer, applied on the right arm of the participants. The average of two readings separated by one minute was taken. Blood pressure was measured by the investigators and interpreted as per the blood pressure guidelines, issued in 2003 by the National Heart, Lung, and Blood Institute as shown below ${ }^{3}$.

Table 1: Blood pressure guidelines, issued in 2003 by the National Heart, Lung, and Blood Institute.

\begin{tabular}{|l|l|l|}
\hline Category & $\begin{array}{l}\text { Systolic Blood } \\
\text { Pressure in } \mathrm{mm} \\
\text { of } \mathrm{Hg}\end{array}$ & $\begin{array}{l}\text { Diastolic Blood } \\
\text { Pressure in } \mathrm{mm} \text { of } \\
\mathrm{Hg}\end{array}$ \\
\hline Normal & Less than 120 & Less than 80 \\
\hline Prehypertension & $120-139$ & $80-89$ \\
\hline Hypertension Stage 1 & $140-159$ & $90-99$ \\
\hline Hypertension Stage 2 & More than 160 & More than 100 \\
\hline
\end{tabular}

\section{Data analysis:}

Descriptive statistics such as means and standard deviation were used to summarize the quantitative variables. The association between age, gender, nationality and blood pressure were determined by Pearson's correlation coefficients. A p-value $\leq 0.05$ was considered for statistical significance.

\section{Results}

A total of 110 students, 26 males and 84 females participated in the study. The age ranged from 17 to 23 years. Table 1 and 2 show the mean Systolic and Diastolic Blood Pressure according to age, gender, physically active/ less active, and nationality. Means of both Systolic Blood Pressure (SBP) and Diastolic Blood Pressure (DBP) were almost similar in the students of different age. The mean SBP among male participants was $122.23 \pm 13.6$ and among females it was $110.75+11.5$. The difference observed was statistically significant $(p<0.001)$. The mean DBP was $77.28 \pm 14.19$ and $72.58 \pm 10.0$ in both males and females respectively but the difference in DBP observed in males and females was not statistically significant.

Means of both Systolic Blood Pressure (SBP) and Diastolic Blood Pressure (DBP) were almost similar in the students of different age. The mean SBP among male participants was 
$122.23 \pm 13.6$ and among females it was $110.75+11.5$. The difference observed was statistically significant $(p<0.001)$. The mean DBP was $77.28 \pm 14.19$ and $72.58 \pm 10.0$ in both males and females respectively but the difference in DBP observed in males and females was not statistically significant.

The mean values for both SBP and DBP were slightly higher among those who led a physically active life when compared to those less active but the difference observed was not statistically significant.

Table1. Mean Systolic \& Diastolic Blood Pressure according to Gender \& Age

\begin{tabular}{|c|c|c|c|c|c|}
\hline \multirow{2}{*}{$\begin{array}{c}\text { Blood } \\
\text { pressure }\end{array}$} & \multirow{2}{*}{$\begin{array}{l}\text { Age in } \\
\text { years }\end{array}$} & \multicolumn{2}{|c|}{ Male } & \multicolumn{2}{|c|}{ Female } \\
\hline & & Mean & SD & Mean & SD \\
\hline \multirow{8}{*}{ Systolic BP } & 17 & 112.75 & 4.65 & 109.68 & 12.01 \\
\hline & 18 & 123.63 & 11.01 & 113.37 & 11.47 \\
\hline & 19 & 143.75 & 6.01 & 105.33 & 10.72 \\
\hline & 20 & 122.00 & 23.22 & 110.89 & 10.78 \\
\hline & 21 & 126.00 & 5.57 & 116.14 & 11.01 \\
\hline & 22 & 109.25 & 6.72 & 115.50 & 6.36 \\
\hline & 23 & 122.00 & 11.79 & 104.33 & 14.98 \\
\hline & Total & 122.23 & 13.61 & 110.85 & 11.54 \\
\hline \multirow{8}{*}{ Diastolic BP } & 17 & 69.50 & 11.27 & 70.12 & 8.04 \\
\hline & 18 & 77.38 & 13.41 & 74.13 & 10.82 \\
\hline & 19 & 96.75 & 15.91 & 70.40 & 6.65 \\
\hline & 20 & 72.13 & 20.95 & 70.50 & 11.08 \\
\hline & 21 & 77.00 & 13.00 & 79.21 & 11.32 \\
\hline & 22 & 80.75 & 1.77 & 74.00 & 5.66 \\
\hline & 23 & 79.33 & 13.05 & 76.00 & 18.33 \\
\hline & Total & 77.29 & 14.19 & 72.73 & 9.96 \\
\hline
\end{tabular}

The mean of both SBP and DBP were however higher in the Arab nationals when compared to non Arab nationals. The difference in the means of SBP and DBP was not statistically significant. The Pearson's Correlation Coefficient was applied to assess the correlation between mean SBP and DBP with age. There was no statistically significant correlation between age and mean SBP and DBP. But there was a significant positive correlation between mean SBP and DBP $(r=0.61)$.
Table 2. Mean Systolic and Diastolic Blood Pressure according to Gender, Physical activity and Nationality

\begin{tabular}{|c|c|c|c|c|c|c|c|}
\hline \multirow{2}{*}{ Variables } & \multirow{2}{*}{ Group } & \multicolumn{3}{|c|}{ Systolic Blood Pressure } & \multicolumn{3}{|c|}{ Diastolic Blood Pressure } \\
\hline & & Mean & SD & p & Mean & SD & p \\
\hline \multirow{2}{*}{ Gender } & Male & 122.23 & 13.61 & \multirow[t]{2}{*}{$<0.001$} & 77.29 & 14.19 & \multirow{2}{*}{ NS } \\
\hline & Female & 100.75 & 11.50 & & 72.58 & 10.0 & \\
\hline \multirow{2}{*}{ Physically } & Active & 113.73 & 12.96 & \multirow[t]{2}{*}{ NS } & 73.91 & 11.63 & \multirow{2}{*}{ NS } \\
\hline & Less active & 111.09 & 13.02 & & 71.72 & 6.88 & \\
\hline \multirow{2}{*}{ Nationality } & Arabs & 117.19 & 11.65 & \multirow[t]{2}{*}{ NS } & 77.30 & 11.66 & \multirow[b]{2}{*}{ NS } \\
\hline & Non Arabs & 110.98 & 13.23 & & 71.30 & 10.36 & \\
\hline
\end{tabular}

Family history of metabolic diseases like hypertension, diabetes mellitus, kidney diseases, stroke and cardiovascular diseases were enlisted and analyzed but the mean SBP and DBP showed no association.

\section{Discussion}

Unlike other studies ${ }^{11-13}$, the present study shows that systolic and diastolic blood pressures were evenly distributed across all students irrespective of age. Oghagbon et $\mathrm{al}^{12}$ in a study of blood pressure among four hundred and sixty four undergraduate students undergoing medical examination as part of entry process, observed a prevalence of $3.4 \%$ and it was more common in males. Mean systolic and diastolic pressures were significantly higher in males than females. A blood pressure screening conducted by McCubbin et al., among 167 college students observed a gender effect on systolic blood pressure and this was explained as a higher reported incidence of "white coat hypertension" among participants especially in females. But the present study does not support the above observation $^{14}$.

Pyle et al. conducted a study to examine the prevalence of elevated blood pressure readings in a group of college students attending an annual oral health program and observed that $13.4 \%$ had elevated blood pressure showing an association with male gender ${ }^{15}$. In the present study there was a significantly higher SBP in males when compared to females but the difference was not significant in DBP. Bertsias et al. report a higher prevalence of raised blood pressure among medical students of University of Crete, much higher than other studies on similar population $^{16}$. Another study among medical students in New Jersey reported high SBP, DBP at percentages of 3.5, $4.2 \%$ respectively ${ }^{13}$.

A survey among medical students at Louisiana State University reported rates of high SBP (4\%) for both men and women ${ }^{17}$. Kashani et al in their study on cardiovascular risk factor assessment among medical students in the University of California - San Diego reported that $8.7 \%$ had high SBP or $\mathrm{DBP}^{18}$. In the present study among medical and allied health science students, the distribution of blood pressure was not associated with age but higher blood pressure was associated with male gender more so for SBP. 
Among participants of the present study, those who led a physically active life showed slightly higher mean SBP and DBP when compared to those less active. This lifestyle behavior was probably the result of awareness about their risk of metabolic diseases. A study among Black and Indian medical students in South Africa comparing their blood pressure profile showed rates of high blood pressure as 2.5 and $4.2 \%$ respectively with a higher systolic and diastolic blood pressure among black students throughout the day, night and critical time periods ${ }^{19}$. Nationalities were grouped as Arabs and Non-arabs in the present study. NonArabs included mainly students from Indian subcontinent and Africa. The mean SBP and DBP were seen to be higher among Arabs when compared to Non-Arabs though not statistically significant. Family history of metabolic diseases did not show any association with the mean SBP and DBP. The small study population and error in reporting of family history may explain this unexpected insignificant association. Whereas other studies show that normotensive offsprings of hypertensive subjects are found to be at higher risk for development of hypertension. Children with a positive family history of hypertension show higher SBP levels than subjects with a negative family history ${ }^{20-22}$. It shows a proxy for genetic susceptibility.

\section{Conclusion}

The study showed a strong association for developing hypertension in male youth when compared to female gender. Further investigations in other similar settings with larger study population are needed to support the findings of the present study.

\section{References}

1. Kannel WB, Castelli WP, McNamara PM, Mckee PA, Feinleib M. Role of blood pressure in the development of congestive heart failure: The Framingham Study. N Engl J Med 1972;287(16):781-7.

2. Tsioufis C, Kyvelou S, Tsiachris D, Tolis P, Hararis G, Koufakis $\mathrm{N}$, et al. Relation between physical activity and blood pressure levels in young Greek adolescents: the Leontio Lyceum Study. Eur J Public Health. 2011 ;21(1):63-8.

3.Kasper DL, Braunwald E, Fauci AS, Hauser S, Longo D,Jameson JL, Loscalzo J. Harrison's principles of internal medicine(16th ed.). New York: McGraw-Hill Medical Publishing Division. 2005.

4.Supratik B, Ganaraja B, Ramesh Bhat M. Correlation between the blood groups, BMI and pre-hypertension among medical students. J Chin Clin Med 2010;5(2):78-82.

5.The Guidelines Subcommittee of World Health Organisation-International Society of Hypertension (WHOISH) Mild Hypertension Liason Committee: 1999 WHOISOGuidelines for the management of Hypertension. J.Hypertens 1999;17:151-83.

6.Gan SKE, Loh CY, Seet B. Hypertension in young adults- an under estimated problem. Singapore Med J 2003;44(9):44852.

7.Khatib OMN, El-Guindy MS. Clinical guidelines for the management of hypertension. Cairo, WHO EMRO Technical publication series, 2005.

Nepal Journal of Epidemiology 2011;1(3):86-89

Copyright @ 2011 INEA

Published online by NePJOL-INASP

www.nepjol.info/index.php/NJE
8.Lenfant C, Chobanian AV, Jones DW, Roccella EJ; Joint National Committee on the Prevention, Detection, Evaluation, and Treatment of High Blood Pressure. Seventh report of the Joint National Committee on the Prevention, Detection, Evaluation, and Treatment of High Blood Pressure (JNC 7): resetting the hypertension sails. Hypertension. $2003 ; 41(6): 1178-9$.

9.Bao W, Threefoot SA, Srinivasan SR, Berenson GS. Essential hypertension predicted by tracking of elevated blood pressure from childhood to adulthood: the Bogalusa Heart Study. Am J Hypertens 1995;8(7):657-65.

10.National High Blood Pressure Education Program Working Group on High Blood Pressure in Children and Adolescents: The fourth report on the diagnosis, evaluation, and treatment of high blood pressure in children and adolescents. Pediatrics 2004;114(2):555-76.

11.Krishna P, Bajaj S, Thennarasu K, Desai N, PrasannaKumar KM. Regional differences in the reference blood pressure in young Indians. Indian Paediatr 2007; 44 (12):921-3.

12.Oghagbon K, Odili V, Nwangwa E, Pender K. Body mass index and blood pressure pattern of students in a Nigerian University. Int J Health Res 2009;2(2):177-82.

13.Najem GR, Passannante MR, Foster JD. Health risk factors and health promoting behavior of medical, dental and nursing students. J ClinEpidemiol 1995;48(6):841-9.

14.McCubbin JA, Wilson JF, BruehI S, Brady M, Clark K, Kort E. Gender effects on blood pressures obtained during an oncampus screening. Psychosom Med 1991;53(1):90-100.

15.Pyle MA, Lalumandier JA, Sawyer DR. Prevalence of elevated blood pressure in students attending a college oral health program.Spec Care Dentist 2000;20(6):234-9.

16.Bertsias G, Mammas I, Linardakis $M$, Kafatos A. Overweight and obesity in relation to cardiovascular disease risk factors among medical students in Crete,Greece. BMC Public Health 2003;3:3.

17. Farris R, Strada R, Wolf T, Suskind R. Nutrient intake and cardiovascular risk factors of first-year medical students. J Vasc Med Biol 1994;5:138-43.

18.Kashani I, Kaplan RM, Criqui MH, Nader PR, Rupp JW, Sallis JF, et al. Cardiovascular risk factor assessment of medical students as an educational tool. Am J Prev Med 1992;8(6):384-8.

19.Morar N, Seedat YK, Naidoo DP, Desai DK. Ambulatory blood pressure and risk factors for coronary heart disease in black and Indian medical students. J Cardiovasc Risk 1998;5(5-6):313-8.

20.Lauer RM, Clarke WR. Childhood risk factors for high adult blood pressure: the Muscatine Study. Pediatrics 1989;84(4):633-41.

21.Cook BB, Treiber FA, Mensah G, Jindal M, Davis HC, Kapuku GK. Family history of hypertension and left ventricular mass in youth: possible mediating parameters. Am J Hypertens 2001;14(4):351-6.

22.Munger RG, Prineas RJ, Gomez-Marin O. Persistent elevation of blood pressure among children with a family history of hypertension: the Minneapolis Children's Blood Pressure Study. J Hypertens 1988;6(8):647-53. 